\title{
INSTRUÇÃO PÚBLICA NOS RELATÓRIOS OFICIAIS E NA CORRESPONDÊNCIA DO IMPÉRIO: BISPO, ASILO E ULTRAMONTANISMO.
}

Fernando Arthur de Freitas Neves

Universidade Federal do Pará (UFPA)

fafn@ufpa.br

\section{RESUMO}

A caridade no império do Brasil da segunda metade do século XIX foi um dos instrumentos para viabilizar a Instrução Pública. A educação voltada para o trabalho teve na igreja do Pará um defensor que mobilizou a sociedade civil e o estado para confiarem esta tarefa à religião oficial do império como um agente de modernização. Esta ação constituía parte da pastoral de D. Macedo Costa de solidificar o campo católico ante as transformações em curso no mundo do trabalho

Palavras-chave: instrução pública, caridade, previdência social, trabalho, instrução religiosa.

\section{PUBLIC INSTRUCTIONIN OFFICIAL REPORTSAND CORRESPONDENCEOF THE EMPIRE:BISHOP, ASYLUM AND ULTRAMONTANISM}

\section{ABSTRACT}

Charityin the empire ofBrazil in the secondhalf of thenineteenth century wasoneof the instrumentsto enable thePublic Instruction.Education focused onthe job wasthechurchfor a defenderwho mobilizedcivil societyand the stateto entrustthis taskto the official religionof the empire asanagent of modernization. This actionwas partof thepastoralD.CostaMacedoto solidifythe catholic campin the face oftransformations inthe world of work.

Keywork:public education, charity, social security, work, religious education.

\section{Intróito}

A igreja da segunda metade do século conseguiu articular sua intervenção em torno do projeto romanizador cuja estrutura estava na infalibilidade papal; na condenação dos erros do século como casamento civil, cemitério civil, liberalismo, socialismo, latitudinarismo; na validação dos dogmas; na disciplina do clero à hierarquia; na união de estado e igreja e tantas outras propostas para salvar a sociedade do racionalismo como a instrução religiosa dirigida pela igreja católica, particularmente na solidificação e a expansão das instituições escolares confessionais. ${ }^{1}$ Se cultura religiosa dispunha de centros especializados para formação de religiosos como os seminários, estes não eram suficientes para preencher o vasto campo de reprodução dos valores católicos na moderna sociedade em vias de secularização.

Se o diagnostico feito pela hierarquia ultramontana quanto às fragilidades dos seminários foi reconhecido por esta e recodificado até seu âmago, a instrução pública sob responsabilidade do estado não era mais animadora, sobretudo quando considerando o trabalho como meio de formação do caráter religioso e civil. Lúcia Oliveira percorreu o caminho de apreender a modernização da igreja e do estado confiando no grafado das cartas encíclicas de "Pio IX, Leão XIII e Pio X, no período de 1860 a 1903"; contudo se existiu uma linha de força a articular diferente papas nem por isso podemos desconsiderar o peso das descontinuidades entre estes. Se no plano das idéias a difusão dos sacramentos 
salva é pela educação que se obtém o remédio. Leão XIII requer a sacralização da sociedade tanto quanto Pio IX, entretanto, e na prática quotidiana das dioceses que a hierarquia apreendeu a dialogar com o século tão condenado.

As congregações religiosas européias dedicadas à educação no Brasil reproduziram o modelo diocesano para o qual foram formadas, ou seja, incutir o catolicismo romanizador em reação à secularização. No entanto a sociedade capitalista havia dispensado a sacralização católica, sendo necessário criar mediações para habilitar a convivência e a experiência católica nas transformações do mundo do trabalho. Por isso vemos como os bispos buscaram a expansão das instituições educativas confessionais, aliadas a proposição de atualização da caridade e da previdência social como forma de ratificar a igreja no bloco de poder.

\section{Previdência providencia}

Rizzini tem o trabalho de maior fôlego sobre a educação na Amazônia durante o bispado de Macedo; examinando as instituições educacionais centrou seu esforço por entender o Instituto da Providência como ação da lavra do bispo ao mesmo tempo em que a educação torna-se relevante na consideração da sociedade civil como ficou espelhado nos debates na imprensa daquele século reclamando medidas do governo para superar as agruras. A instrução púbica conquistou posições nas capitais, embora as províncias do Pará e Amazonas continuassem a testemunhar a ausência de política pública a remediar a falta endêmica de escolarização comum em todas outras províncias. Estadistas ainda no império tentaram responder essa fragilidade como apontou Murasse em "A educação no processo de organização e consolidação do império do Brasil: o pensamento de Bernardo Pereira de Vasconcellos (1795-1850) e de Zacarias de Góes e Vasconcellos (1815-1877)"² quando reforçaram a idéia de focar a educação voltada para o trabalho sem jamais desprender-se da função moralizadora. Correlato a noção de Vasconcelos e Vasconcelos, José Liberato Barroso demonstra quão incomoda era a situação da instrução pública quando se avizinhava os limites à reprodução da escravidão e quanto era reduzido à oferta da escola primária. Percebe-se a conformação de outros atores na sociedade civil ao lado de estado e igreja buscando atualizar o Brasil com o século na promoção do progresso a partir da indústria e do comercio constituindo inclusive as primeiras escolas noturnas com a ênfase na educação primária para aqueles que necessitados desta formação prévia para manipular os ofícios requeridos na modernização.

Os esforços de D. Macedo Costa, portanto, estavam em sintonia com ansiedades do século e as proposições deste responderam as expectativas de ofertar instituições educacionais profissionalizantes para um mercado de trabalho capitalista em formação.

Espiritualidade e moralidade foram dois signos perseguidos pela igreja ultramontana no afã de certificar-se do campo católico como eixo de redenção religiosa e social. Plasmar essa tese, tendo no episcopado seu principal irradiador, implicou na mobilização do campo católico nas lides com o estado quando tinha a oportunidade de oferecer propostas da sociedade tradicional no intuito destas serem absorvidas na modernização do estado brasileiro da segunda metade do século XIX. Com efeito, a preocupação da igreja com os desafortunados foi um dos elementos mais graves na ação pastoral; a legislação de previdência social engatinhava, tendo as sociedades beneficentes e caixas de Montepio os poucos instrumentos de auxilio a pobreza, embora as ferramentas de solidariedade inscritas nas confrarias continuassem ativas, faltava política de estado para responder o crescimento das dificuldades da população do país, particularmente da Amazônia compreendendo as províncias do Pará e Amazonas. D. Macedo Costa, bispo da diocese que reunia as duas províncias não inova em relação ao século, renova sua crença 
nos institutos históricos de caridade ampliados pelos organismos edificados ao longo do século XIX para acolher as crianças em desamparo, para tanto propõe o funcionamento do "Asilo de Órfãos e Desvalidos" para funcionar no Convento do Carmo".

A igreja creia ser sua tarefa a assistência social ficando o estado com a incumbência de financiamento. Os asilos, as escolas, as bolsas de estudos para crianças pobres, a educação das meninas foram temas recorrentes nos discursos do bispo; por muitas correspondências ele procurou trazer para sua diocese religiosos e religiosas para cuidarem da reta formação moral e espiritual, mas não descuidou da necessária introdução do trabalho, em consonância com a cultura do século no qual este sedimenta uma ética na modernidade, conferindo ao mesmo, embora não sozinho, como meio eficaz de alcançar moralidade entre os fiéis, sobretudo quando colocados diante de possíveis ameaças como as imigrações de protestantes, a abertura do Amazonas à navegação internacional, a desorganização e falta de zelo no seminários, a imigração de nordestinos empurrados para floresta pela seca e o aumento da exploração da borracha no interior dos sertões ${ }^{4}$. Recorrendo ao estado procurou solidariedade nestes projetos civilizatórios ao lançar-se diretamente em empreendimentos econômicos para subsidiar a política de sustento do campo católico imerso na secularidade com exemplo no requerimento para medição de terras devolutas para criação de gado ${ }^{5}$ em favor da assistência social da igreja; o ministro do império Conselheiro Pedro Leão Veloso foi instado a gerar dotações orçamentárias para Escola de Agricultura, Artes e Ofícios ${ }^{6}$, recomenda ao estado não se deixar seduzir por falsos documentos comprobatórios de compra de terras aonde tinha ficado para ser o estabelecimento da escola proposta pelo bispo ${ }^{7}$. A falta de recursos contínuos fez D. Macedo recorrer constantemente ao estado para prover o Estabelecimento da Providencia ${ }^{8}$. $\mathrm{Na}$ diocese tão grande, quarenta alunos da província do Amazonas, das localidades do Rio Negro e do Rio Solimões, vindos para o Estabelecimento da Providencia ali foram abrigados, entre setenta e cinco lá residentes; entretanto os críticos liberais desconfiavam da proposição do prelado, perscrutando um conjunto de intenções ultramontanas recobrindo as propostas de oferta de educação e questionavam as intenções do bispo publicamente no Jornal do Comércio pelo polemista Niemayer. Se posta para defender o bispo o senhor Grifening ao exemplificar as falhas da Assembléia Provincial do Amazonas quando dotou o orçamento provincial em 25:000\$000 inicialmente, mas por ter sido fechada aquela legislatura não chegou a ser executado o ordenamento das custas. Relata que já fazia quatro anos os alunos provenientes da província do Amazonas estavam na Escola da Providencia "sem pagar a mínima pensão", sobrevivendo da obra de caridade feita com os donativos arrecadados pelo bispo do Pará em Minas Gerais e Rio de Janeiro. Todavia fosse sofrível o sustento do empreendimento religioso, existiam em suas dependências serrarias e maquinismo a espera de serem montados além da necessidade de novas casas para abrigar bem aos moços e equipagem para qualificação da força de trabalho requerida nos processos de modernização do capitalismo; só de donativos era insuficiente o amparo, era preciso financiamento continuo para Escola sob pena daquela vir a falir; as opções para ampliar o sustento da obra não eram muitas e desagradava ao bispo ter de dividir as fontes de financiamento com outras propostas civilizatórias criadas por seu múnus pastoral; destarte, as loterias existentes tinham o intuito de viabilizar a cristianização nos rios da Amazônia e não deveriam ser desviadas de suas finalidades, estas eram para o sustentar o projeto Cristoforo" poder "derramar a luz do evangelho no valle do Amazonas", colocando a nu as contradições do poder civil com o financiamento, pois se a assembléia provincial anuiu ao pleito da igreja, o presidente da dita província diz ser imoral a loteria como jogo financiar um projeto religioso, portanto, declarou ser a lei imoral $^{10}$. D. Macedo não costumava ser tolerante com os costumes do século, mas 
acreditava ser razoável dirigir o infortúnio do jogo para suprir a demanda romanizadora de levar o catolicismo de sacramentos às populações até então confortadas tão somente pelo culto dos santos do catolicismo devocional. Em oposição ao prelado a moralidade do presidente da província serviu para obstar o pagamento das contribuições à Escola da Providência e desincumbir-se de ofertar escola e profissão a uma parcela dos jovens da província do Amazonas.

Outras iniciativas são difíceis de serem acompanhadas, entrementes estivessem no mesmo circuito como o empreendimento para construção de um prédio para asilo da infância desamparada, apelando a quem tem poder, sem identificar, "cuja coragem bem fazer me é conhecido ... favor ajudar na obra tão humanitária e caridosa dando por esmola algum material de que fabrica em seu estabelecimento. Essa esmola será mui grata a Deus e atrahira sobre a casa de V. S. copiosissimas benção" ". A gestão do estado podia parecer tímida, mas não foi omissa, ela procurou oferecer os meios para o desenvolvimento material das províncias nos quadros da cultura letrada como foi no Grão-Pará pela portaria de 31/8/1877, manifesto na intervenção do diretor de instrução pública, Dr. Américo Santa Rosa, distribuindo livros para os alunos que freqüentavam as escolas da Província do Pará $^{12}$.

Naquele período não houve iniciativas financiadas direta e permanentemente pelo poder central para a Amazônia, salvo algum ordenamento explicito como demonstramos. Os relatórios das pastas do ministro dos Negócios do Império e do ministro da Agricultura descrevem até onde foram os compromissos com estes estabelecimentos, restando às províncias suprirem com o grosso dos recursos à promoção da assistência social aquele tempo incorporando a instrução pública. A falta de política para este segmento agitava a consciência nacional, mas foi o bispo quem politizava e questão ao espiritualizá-la colocando-a sob o manto da caridade; sem ficar preso às injunções sectárias de plantão atravessa a moralidade ao sujeitar o jogo ao fim nobre da evangelização com o Cristoforo. A prática de esmolação tão criticada nas folias dos santos pelo ultramontanismo do bispo foi resgatada para acudir os infantes desamparados. Todos esses expedientes, esmolas e loterias, são desculpados pela liderança da igreja no intuito de suprir de auxilio a ausência de financiamento para estas demandas, senão quando às vezes aprovadas, acabava por ser marginalizada pelos escrúpulos de consciência do poder civil incrustado na presidência de uma província como foi o caso narrado.

Tendo de haver-se com o poder provincial não apenas com o financiamento no caso do Amazonas, mas também com o espaço físico no lugar a sediar o empreendimento como era o Pará, D. Macedo opôs as especulações feitas com os terrenos adjacentes da "Providencia", pois o governo imperial havia determinado a demarcação das terras devolutas para que fossem ordenadas com o fim de servirem aquele estabelecimento, pedindo ao juiz comissionar o que fazer para dar estatuto legal aquela ocupação sob direção da igreja. Presidindo a província do Pará, o conselheiro João Antonio Freitas Henrique não depositou aos pés do bispo nem receita para esta ação, em contrapartida tentou dar a outro particular o pouco cedido, as sobreditas terras, pelo governo do império merecendo a desaprovação do bispo que se encontrava em Manaus ${ }^{13}$. Esta foi uma batalha árdua entabulada pelo antístite, mas os argumentos deste foram reconhecidos pelo império tal como prova o Aviso Ministerial de 2/5/1883, doando o terreno para o Estabelecimento Agrícola e Industrial da Providencia ao lado da Estrada de Ferro de Bragança nos lotes 13, 15, 17, 19 e 21, embora houvesse ambições de particulares sobre estas terras como os pedidos de compra feitos por Joaquim Antonio Costa e outros, alegando serem possuidores de trezentas braças terras de frente e de fundo, vizinhas a estas. Recomenda o bispo não ser tituladas as terras a que se quer comprar/vender sem a previa demarcação das terras da 
"Providencia" já orçadas e com recursos definidos pelo ministério da agricultura; somente depois de cumprido o Aviso Ministerial seria conveniente proceder as demais demarcações sem o aproveitamento por parte de Joaquim Antonio Costa para requerer as ditas terras, ${ }^{14}$ sustentava o ardil do prelado.

A valorização das terras cortadas por estradas de ferro no mundo alcançou uma magnitude espetacular, exceto quando se tornaram falidas por crises econômicas ou quando tragadas pela natureza. Disputadas estas terras pelos empreendedores capitalistas, pouco apoio podia a igreja granjear; sem ter acesso ao recurso da compra teve de valer-se da solidariedade ativa do estado para poder postar esta intervenção ${ }^{15}$. O valimento foi justificado com o projeto de formação de mão de obra e serviços a serem prestados à modernização em curso na província, pois faltavam materiais e operários qualificados nas funções, por isso o investimento nas serrarias e maquinismo no estabelecimento Providencia. A perspectiva dos particulares foi fazer render aquelas terras desde a especulação gerada com o aquecimento do mercado de terras até então pouco atraente, mas potencializado pelo trajeto da ferrovia sinalizava uma oportunidade de lucro logo despertada instando o bispo a salvaguardar um espaço econômico para reprodução material das profissões, enquanto projetava a formação católica naqueles assistidos pela caridade da igreja.

As contestações se multiplicaram, Vitorino José do Couto Quintanilha queria as terras aventadas para sediar a Providencia, continuou embora sem sucesso perseguir na confirmação da posse de terras, abusando ou ainda se utilizando dos muitos recursos de pressão política para romper as determinações do governo do império. Escudada neste último a igreja consegue ser firme em seu desiderato, o governo da província não podia confronta-se abertamente com a diocese e acabou atendendo ao pleito desta contra um particular para formar na província os meninos pobres com a oferta de ofícios em agricultura e artes (operário) necessários ao mundo do trabalho, segundo os padrões vigentes de civilização.

Uma vez mais a tentativa de compra foi o expediente para legitimar o que o bispo considerava um seqüestro das terras pertencentes ao dito estabelecimento habilitando a lei 601 de 18/9/1850, refutando sua aplicação por não se tratar o caso devido a estas terras atenderem à utilidade pública da escola patrocinada pelo bispo, com o reconhecimento do governo do império, empenhado em favorecer a criação de institutos desta ordem para prover de modo eficiente a "educação moral e a instrução técnica dos pobres filhos do povo", e não ao interesse pessoal de enriquecer com a transação. D. Macedo usa este argumento para conferir um juízo comum da igreja e do estado solidários no progresso material do povo, ao estender a noção de obra de utilidade pública apartar-se da esfera privada descomprometida com a rede de assistência social e instrução pública a remediar as muitas condições de pobreza em seu entorno ${ }^{16}$. Tenho falado de uma falta de política de assistência social por parte do estado no império, no entanto, estas noções não são tão precisas na época, a política de assistência social foi prefigurada como intervenção de caridade mutuamente celebrada por igreja e estado, embora com a precedência da primeira. Por isso D. Macedo invoca o direito sagrado sobre aquelas terras ao possibilitar dirimir as mazelas acometidas contras os "orphãos e pobrezinhos", não cedendo a ninguém o direito de explorá-las sem a cumplicidade com o projeto civilizatório de assistência à pobreza.

O governo do Brasil teve uma postura assimétrica na construção e sustento de estabelecimentos de assistência social, o privilegio da província do Rio de Janeiro ficou obvio nos relatórios da pasta da agricultura, conquanto tenha contado com institutos desta estirpe em outras províncias. D. Macedo não conseguiu estatuir o financiamento regular para o Asilo da Providencia como seus congêneres haviam obtido com dotação 
orçamentária anual descrita nos referidos relatórios, porém irmana a escola na diocese do Pará na finalidade de atender aos necessitados dando-lhes um oficio em que se empregar, somado ao compromisso de injetar e difundir os conhecimentos tomados como fundamentos da civilização. A descrição do estabelecimento estava orientada em grande parte para o mundo rural, reflexo da importância econômica e da capacidade de reprodução social e simbólica da sociedade tradicional atestada nos relatório apresentados "pelo ministro e secretario de estado dos negocios da agricultura, commercio e obras publicas, Afonso Augusto Moreira Penna", senão vejamos "Colônia Orphanologica Blasiana. Esta colonia tem, como sabeis, a sua sede na fazenda da Conceição a 18 kilometros da cidade de Santa Luzia, á margem esquerda do rio Corumbá, na provincia de Goyaz, e dá educação a 34 orphãos sendo um ingenuo. As disciplinas constam de lingua nacional, geometria, desenho, arithmetica, geographia e historia do Brazil, doutrina christã, musica vocal, principios de agrilogia, principalmente os de zootechnia no ponto de visto de economia rural, principios de economia agricola e o manejo de instrumentos agrarios. Dispõe a colonia de varios edificios e é regida pelo Dr. Joseph de Mello Alvares. Tem sido ensaiada com feliz exito, a criação de gado vaccum, cavallar, ovelhum, cabrum e suino e a de aves domesticas. A colonia, além de uma plantação de 600 rnarmelleiros, 8.000 cafeeiros, 1.500 videiras, 3.600 bananeiras, cultiva a canna de assucar, baunilha, mandioca e outras especies de tuberculos, juta, algodão e fumo, e diversas especies de cereaes, cujos productos são destinadas a consumo. Esta escola recebe dos cofres publicos o auxilio annual de 500\$000"17.

Não há sequer uma ocupação geopolítica na distribuição de institutos desta natureza sob controle do governo central. As províncias por sua iniciativa poderiam estatuir estes escolas voltadas aos ofícios..., quanto a cair nas graças do poder incrustado na corte isso diz respeito às proximidades efetivamente conquistas no bloco de poder nacional. A província do Pará definitivamente foi marginalizada neste jogo de forças.

D. Macedo não chegou a ser um pioneiro nesta ação, as proposições se igualam quando reclamam a assistência social como meio de remediar os infortúnios da aceleração do modelo do extrativismo, sobretudo na coleta de borracha pelo brabo, pois acreditava o prelado, como parte da intelligentsia, que apartado o homem da civilização ao se embrenhar na floresta, mais assimilava as determinações daquele meio tão selvagem ${ }^{18}$.

Sem contar com o financiamento ordinário o bispo foi obrigado a improvisar o custeio da empreitada à custa das esmolações sob formas de doações em todo orbe católico, e quando possível das dotações orçamentárias das províncias ${ }^{19}$; os recursos das irmandades também podem ter sido solicitados para auxiliar na manutenção do estabelecimento $^{20}$ devido à fragilidade da política nacional para organizar institutos assemelhados. Em favor do bispo ficou a proposição acolhida posteriormente pelos republicanos quando edificou a Escola de Artes e Ofícios Lauro Sodré, nome de um dos desafetos de D. Macedo. Às vezes a saída foi à entrega da gerencia destes institutos para ordens religiosas como foi o caso do convite feito às Irmãs Doroteias para cuidarem do Azilo de Santo Antonio, voltado para educação de meninas ${ }^{21}$. A proibição do noviciado deixou desocupado algumas propriedades como o convento do Carmo, em Belém, permitindo ali ser instalado um educandário para assistir às meninas desvalidas ${ }^{22}$.

Aliando-se à causa da promoção da educação, o antístite do Pará estimulava a expansão da cultura letrada como sinônima de civilização, esperava com esta medida sanar a falta de acesso aos bens espirituais e materiais potencializados com a habilidade da leitura. Este consenso das elites letradas moveu algumas ações, contudo o estado não era capaz de suportar este quesito do desenvolvimento suscitando a criação de organismos a animar a constituição de escolas e cursos para uma vez interiorizado este preceito na 
consciência nacional, o país pudesse gozar da implementação de uma estrutura de instrução pública bem como dos produtos realizados a partir desta. Os relatórios da instrução pública demonstram como a situação nas províncias eram uma lastima, a falta de professores qualificados e a remuneração ínfima dificultava sobremaneira o sucesso da empresa, ${ }^{23}$ se fossemos considera a falta de livros didáticos, a falta de preparo pedagógico e às péssimas condições das edificações estaríamos a exigir demais do século XIX, pois como sabemos a noção de educação universal ainda engatinhava; mais significativos foram à intervenção de particulares para minorar este quadro instando a redenção dos homens livres pobres, particularmente aqueles recém saídos da escravidão ou daqueles colocados diante de uma nova condição como foi o caso da promulgação da lei do ventre livre.

Civilizar os incultos requeria a adoção de um hábito civilizatório como os observados nas "nações adiantadas", a hierarquia católica mostrava o exemplo ao inaugurar a Biblioteca Eclesiástica de Belém em 19/3/1872, ali seriam reunidas não somente a literatura religiosa, outros títulos foram adicionados e dispostos à consulta, embora atendesse prioritariamente aos clérigos acreditava o bispo no beneficio estendido a outros interessados.

Em consonância com o espírito da época, D. Macedo saudava as intervenções dos governantes na direção de difundir o saber letrado na província do Pará através da criação da Biblioteca Pública em Belém, sob a direção do governo de Joaquim Pires Machado Portella, no período curto da presidência foi notado e dado como exemplo aos outros homens de estado, e convida o clero a cooperar com a doação de livros e a incitar a população na freqüência destes estabelecimentos. ${ }^{24}$

\section{Estado indutor da educação e a batalha pelo clero romanizado}

O estado da instrução pública nas províncias do Amazonas e Pará ${ }^{25}$, circunscrevendo a mesma diocese, era assemelhado. Sendo a última mais povoada e liderando a região esta não chega a ter um diferencial em termos de promoção da instrução pública, em termos absolutos obviamente a representatividade das escolas chega a ser três vezes maior, entretanto em termos relativos padece da dificuldade de imprimir uma opção pela valorização da instrução pública. Os investimentos do estado para inculcar os valores da civilização precisavam da solidariedade da igreja ocupando-se da formação do clero para ensinar a espiritualidade e a moralidade; desde a posse no bispado D. Macedo procurou colocar seus iniciados na carreira eclesiástica dentro do modelo ultramontano e recebeu respostas positivas do bispo de Marselha, D. Latria, aceitando dois seminaristas (para o pequeno seminário) $^{26}$, não tendo o mesmo sucesso com D. Felix, bispo de Orleans, apesar de reconhecer o zelo sacerdotal não pode atender o pedido de recebimento de estudantes brasileiros devido a pobreza daquele seminário, nem dispor de auxiliares para se deslocarem para a diocese do Pará, irmanado nas lutas da igreja tinha suas próprios problemas e sugere pedir socorro com as ordens religiosa italianas acossadas pelo movimento de unificação nacional, limitando os espaços de sua atuação, talvez se sentissem atraídas para desenvolverem o trabalho de missão nestas novas terras ${ }^{27}$.

Devotado à causa ultramonta, D. Macedo recusa a civilização nos termos liberais, aqueles experimentados longamente na educação de jovens foram preteridos por não aceitarem as teses da romanização e foram forçados a demitirem-se da docência do seminário, como foi o caso de Padre Eutychio, após doze anos como lente na matéria, fora taxado de inimigo da independência da igreja por ter questionado junto a outros lentes os postulados do bispo, mas manobrava bem quando dizia "ser apenas um padre" contra um bispo em sua diocese. A querela para o líder da igreja era dogmática, por isso remove o 
padre das suas funções para precaver-se da pureza do ensino da disciplina Dogmática calcado no direito canônico, afirmando ser o " $1{ }^{\circ}$ Guarda e responsável", enquanto o padre alega ser a razão o melhor juízo não se tratando de dogmática $^{28}$ e ratificava sua compreensão sem subserviência. A autoridade é quem julga e para D. Macedo esta era a questão. O zelo confiado pela igreja ao padre em doze anos havia passado, o preclaro bispo refutava seus ensinamentos, não há mais lugar para o católico ilustrado nas cadeiras do seminário. Padre Eutychio continuou sua saga pela civilização liberal em combate à civilização ultramontana.

Estas posturas agressivas do bispo deviam-se ao compromisso de recompor as bases orgânicas para a constituição do campo católico e a defesa para da sociedade tradicional, acautelou-se com a instituição do clero como um artífice do poder religioso observado sua operacionalização no campo ao resguardá-lo da influencia do liberalismo católico devido à contumácia em restringir a mobilidade da igreja. $\mathrm{O}$ ensino da doutrina cristã nas escolas por clérigos ultramontanos era o desejável, na impossibilidade era preciso podar a autonomia de ensinamento para não se voltarem contra a religião oficial do império muito menos das diretrizes impostas pela hierarquia alinhada às orientações de Roma.

Desafio correlato à falta de clérigos nas paróquias era a falta de professores nas escolas e o baixo valor da remuneração agravava o problema material e espiritual, quando considerados os lugares mais distantes da capital a falta de assistência religiosa e de instrução pública foram objeto de revisão. O ideal civilizatório continuou a plasmar as ações de estado e igreja, mas a capacidade de ocupar os postos de trabalho ficou aquém das necessidades como relatam os presidentes de província ${ }^{29}$ e os ministros dos Negócios do império. Na região de contestado do Brasil e França nem estado nem igreja agiam satisfatoriamente, a carência de agentes públicos do padroado colocava em risco até a soberania do lugar obrigando uma resposta imediata do império, por via do poder da província, para assegurar sua presença no lugar.

Ultrapassando o período da Questão Religiosa, os compromissos de atender a população retratam a solidariedade ativa do estado ao confiar à igreja a execução da educação no seminário episcopal por considerarem "este estabelecimento mantido pelo governo geral e pelo virtuoso Bispo Diocesano comprehende o curso superior ecclesiastico, um curso completo de humanidades e outro de instrucção primaria e tem dado aos exames geraes alumnos bem preparados" 30 . Os liberais no poder da província não romperam a aliança, acompanharam o sustento do governo central, como está explicito nas legislações ordinárias aprovadas pela assembléia provincial do Pará, apesar dos ânimos não terem arrefecido completamente devido a Questão Nazarena ${ }^{31}$ e continuar a gerar embaraços entre estado e igreja; a penúria da assistência espiritual foi semelhante em outras províncias como ficou grafado pelo poder civil ao constatar no arcebispado da Bahia das 249 freguesias ali existentes, 34 estava sem párocos em $1883^{32}$, o quadro da diocese de Goiás era muito menos animador "por falta de sacerdotes ha nesta diocese grande numero de parochias vagas. Para obviar aos inconvenientes que resultam de semelhante falta, o Rev. Bispo trata com toda a solicitude de dar maior desenvolvimento ao Seminario Episcopal, e pede que a este se conceda o auxilio annual de 6:000\$000. Pensa o Rev. Prelado que será de grandes e salutares consequencias o restabelecimento do Seminario de Campo Bello, situado no triangulo mineiro e dirigido pelos Padres da Congregação da Missão",33.

Todas as medidas da hierarquia ultramontana não tiveram sucesso de pronto, o modelo diocesano ao purificar a igreja da influencia do clero liberal teve reduzida a oferta de padres para ocupar as paróquias existentes, agravada pela ampliação das novas 
paróquias criadas e reconhecidas canonicamente pelos bispos nas dioceses, somadas aquelas por reconhecer...; no caso da província do Amazonas a divisão eclesiástica estava distribuída em 32 paróquias, sendo " 8 no municipio da capital, 7 no de Barcellos, 6 no de Teffé, 2 em cada um dos municipios de Borba, Silves e Parintins, e 1 em cada um dos de Coary, Itacoatiara, Maués, Manicoré e Codajás. D'estas, estão instituidas canonicamente 25, e faltam instituir 7. Providas de vigario ha apenas 9 estando vagas 23"34, se administrativamente estado e igreja estatuíam o poder civil na interiorização do império com a instrução pública acompanhado de serviço religioso oficial, não se pode confirmar a regularidade dos mesmos a presentificar a ação destes estatutos gerando uma gama de reclamações.

De forma complementar a experiência religiosa era efetuada sem a presença do sacerdote na maioria das vezes solidificando os modos de "ser católico" tradicional e popular e em menor medida o modo de "ser católico" ilustrado. Com efeito, a civilização era a meta perseguida, mas as condições acabavam sobrepondo-se as intervenções de estado e igreja. Para minimizar o fardo da ausência de religiosos, D. Macedo procurou otimizar a oferta dos serviços simbólicos do catolicismo sob o comando do ultramontanismo nomeando às vezes padres que também eram professores para cumprirem a dupla função, embora este não fosse o desejo do bispo, pois queria dedicação exclusiva à causa da igreja, acabou por ceder diante da realidade e dos exíguos rendimentos dos emolumentos dados ao clero. Mas nem sempre foi assim, as desconfianças do bispo com o proceder de determinados padres o levaram a desconsiderar os pleitos do rebanho e os removia para manter seu controle.

O padre podia celebrar missa em Melgaço donde era pároco e dar aula em Portel onde era professor público, as duas localidades são distantes entre si, os calendários religiosos (Assunção de Maria, Espírito Santo e Trindade) nem sempre podiam ser observados pela remoção do padre ocasionando pedidos dos fieis para preservarem o sacerdote naqueles momentos mais requeridos pela cultura do catolicismo tradicional e popular no momento da festa do santo; este argumento era desaprovado pelo antístite, outros ainda podiam ser compulsados a mudar de atitude e de localidade por serem padres casados ou amancebados, obviamente houve ilações para prejudicar alguns desafetos da política. Padre Mateus Franco foi defendido dessas acusações por seus paroquianos, porém D. Macedo manteve-o afastado dessas localidades.

\section{Em suma}

Houve uma prioridade dos bispos para centralização política e espiritual do clero segundo a orientação da Sé de Roma no confronto com a modernidade e o século. Contudo, o dialogo com as instituições modernizadoras foi aprofundado como revela a intenção dos príncipes da igreja em fundar e manter instituições educacionais com características de previdência social, oportunidade para igreja exercitar a caridade no século, enquanto aprende a considerar o trabalho como valor da nova sociedade capitalista.

Ofertar os serviços simbólicos da religião oficial na convivência religiosa em paralelo com a instrução religiosa no currículo da instrução pública continuou a ser um desafio pela falta de párocos para viabilizar a difusão do catolicismo diocesano. Este estudo não comporta os óbices apontados por liberais e maçons radicais quanto à oferta de ensino religioso na instrução pública. Com efeito, sem privilegio no quadro de escassez, a Amazônia suportou as investidas de particulares pouco sensíveis a necessidade de assistência material por via da educação pública e da educação espiritual. O governo da província e do império foi tensionado pela igreja para prover adequadamente a instrução 
pública naquele período; a liderança de D. Macedo no plano regional e local serviu para credenciar a este como arauto da modernização ao executar a iniciativa do Asilo da Providência formando braços para o mercado de trabalho, cidadãos para o império e fiéis para igreja. Se o numero atendido foi bastante reduzido se comparado com as populações das províncias do Amazonas e Pará, significativo foi o diagnóstico feito pela igreja sobre a necessidade de qualificar a força de trabalho no momento de transição do trabalho escravo para o trabalho livre acoplando a formação religiosa neste processo.

Bibliografia:

BAENA, Manuel. Informações sobre as Comarcas do Pará. Belém - Typ. Francisco Costa Junior, 1885.

BUARQUE, Manuel. Recordações do Xingu. Belém - Papelaria Suissa, 1940.

Murasse, Celina Midori. A educação no processo de organização e consolidação do império do Brasil: o pensamento de Bernardo Pereira de Vasconcellos (1795-1850) e de Zacarias de Góes e Vasconcellos (1815-

1877).http://www.histedbr.fae.unicamp.br/acer_histedbr/seminario/seminario7/TRABALH OS/C/Celina\%20Midori\%20Murasse.pdf.Capturado em 25/6/2011.

PENNA, DomingosSoaresFerreira. Obras completas de DomingosSoaresFerreiraPenna. Belém: Conselho Estadual de Cultura, 1971-1973. 2 v. (Coleção Cultura ParaenseInácio Moura)

PENNA, DomingosSoaresFerreira. Noticia geral das Comarcas de Gurupá e Macapa'. Belém - Typ. Diário do Gram - Pará, 1874.

RIZZINI, Irma; ARAUJO, S. O século das luzes na Amazônia: a instrução pública nas províncias do Pará e Amazonas no Brasil imperial. In: GONDRA, José Gonçalves;

SCHNEIDER, Omar. (Org.). Educação e Instrução nas Províncias e na Corte Imperial (Brasil, 1822-1889). 1 ed. Vitória: EDUFES, 2011, v. 1, p. 15-48.

SANTA ROSA, Henrique Américo. Historia do Rio Amazonas. Belem: Diario Official, 1895.

WAGLEY, Charles. Uma comunidade Amazonica: estudo de homem nos trópicos. São Paulo: Ed. Nacional; Brasília, DF: INL, 1977.

WALLACE, Alfred Russel. Viagens pelo Amazonas e Rio Negro. São Paulo: Companhia Editora Nacional, 1939.

\section{Notas}

${ }^{1}$ Oliveira, Lúcia Helena Moreira de Medeiros. O projeto romanizador no final do século XIX: a expansão das instituições escolares confessionais. Revista HISTEDBR On-line, Campinas, n.40, p. 145-163, dez.2010 ISSN: 1676-2584145. 
${ }^{2}$ Murasse, Celina Midori. A educação no processo de organização e consolidação do império do Brasil: o
pensamento de Bernardo Pereira de Vasconcellos (1795-1850) e de Zacarias de Góes e Vasconcellos (1815-
1877).http://www.histedbr.fae.unicamp.br/acer_histedbr/seminario/seminario7/TRABALHOS/C/Celina\%20
Midori\%20Murasse.pdf.Capturado em 25/6/2011.
${ }^{3}$ Comunicado feito em 24/9/1871. Ramos, Alberto Gaudêncio. Cronologia eclesiástica do Pará. Belém: Falângola, 1985, p 46. A ordem carmelita cede seu convento em Belém para meninas desvalidas em 20/1/1870. (Lata 411, Pasta 64) IHGB: Fundo D. Macedo Costa. Convém salientar a proibição do noviciado em vigor desde 1855 e ausência de uma estratégia eficiente para interessar os moços na carreira eclesiástica.

${ }^{4}$ Cf.Santos, João. A Romanização da Igreja Católica na Amazônia (1840-1880), In: Hoonaert, Eduardo (org.). História da Igreja na Amazônia: ensaios de interpretação a partir do povo, $4^{\text {a }}$ edição, Editora: Vozes, 1994.

${ }^{5}$ Cf: (Lata 411, Pasta 17) IHGB: Fundo D. Macedo Costa.

${ }^{6}$ Em 9/8/1872 o bispado tentava uma parceria com o estado. Cf: (Lata 412, Pasta 64) IHGB: Fundo D. Macedo Costa.

${ }^{7}$ Este documento contestava, portanto, a Vitorino J. de Couto Quintanilha por tentar tomar posse nas terras cedidas para o referido estabelecimento, presumo ser endereçada ao governo, datado de 4/6/1883. Cf: (Lata 411, Pasta 47) IHGB: Fundo D. Macedo Costa.

${ }^{8}$ Oficio ao Conselheiro Augusto Moreira Penna, Ministro da Agricultura de 8/10/1883. Cf: (Lata 412, Pasta 51) IHGB: Fundo D. Macedo Costa.

${ }^{9}$ Barco a vapor idealizado por D. Macedo para acomodar um templo itinerante para fazer a oferta de serviços simbólicos e difundir a pastoral do catolicismo romanizador. Ver: MARTINS, K. D. . A civilização Católica: D. Macedo Costa e o Desenvolvimento da Amazônia na Segunda Metade do Século XIX. Revista de História Regional, Ponta Grossa (Pr), v. 7, n. 1, p. 73-103, 2004 e Cristóforo e a Romanização do Inferno Verde: as propostas de D. Macedo Costa para a civilização da Amazônia (1860-1890). Campinas: Tese de Doutorado apresentada ao PPG de História da UNICAMP,2006.

${ }^{10}$ Cf: Documento de Manaus s/d completa (1887). (Lata 413, Pasta 21) IHGB: Fundo D. Macedo Costa.

${ }^{11}$ Cf: Documento saiu da Travessa do Atalaia, s/d, sem destino. (Lata 411, Pasta 21) IHGB: Fundo D. Macedo Costa.

12 Ver: CARDOSO, Firmo. A Educação Primária no Regimen Monarchico, in MOURA, Ignácio (org.). Annuario Historico, Litterario e Commercial de Belém, Belém: Impressa Official, 1915.

${ }^{13}$ Cf: Documento à justiça de 4/5/1886. (Lata 412, Pasta 25) IHGB: Fundo D. Macedo Costa.

${ }^{14}$ Há uma impropriedade no documento quando menciona ser a doação na província do Amazonas, pois a estrada de ferro de Bragança é na província do Grão-Pará. Os registros de terras tinham imprecisões acentuadas permitindo a manipulação de interesses denunciados pelo bispo. Documento de 3/12/1886.(Lata 412, Pasta 25) IHGB: Fundo D. Macedo Costa.

15“Paço Episcopal de Belém do Pará 3 de Dezembro de 1886.Ill.mo e Ex.mo Senr.Attendendo benignamente ao que eu ponderei sobre a necessidade de ter o estabelecimento agrícola e industrial da "Providencia" uma larga área de terreno, afim de poder desenvolver-se para o futuro e fazer todo o bem que delle esperam esta província e a do Amazonas, mandou o Governo de Sua Magestade, por Avisos do Ministério da Agricultura e Obras Publicas de 2 de maio e 28 de julho de 1883, reservar para o supramencionado estabelecimento seis kilometros de terrenos devolutos ao lado direito da estrada de Bragança, confinando com os lotes 12, 14, 16, e 18, e 3, 300 metros em quadro do outro lado da estrada, confinando com os fundos dos lotes 13, 15, 17, 19 e 21. Mal foi conhecida esta concessão do Governo em favor de uma instituição caridoza e de tanta necessidade no nosso paiz, começaram as ambições particularesa agitar-se, e vários requerimentos foram dirigidos a Administração da Província pedindo por compra aquelles terrenos. Não obstante a publicidade que tiveram os Avisos do Ministério d'Agricultura, não obstante os esforços que fiz para não deixar ser frustado o acto generoso do Governo Imperial e levado aquelle pio estabelecimento, que tantos sacrifícios me tem custado, logrou sempre Jeronymo Antonio Costa, (e não sei se lograram outros) obter por surpreza títulos provisórios de propriedade de dous lotes, de 500 braças de frente sobre 500 de fundo, cada um, alem do lote da mesma dimensão que já possuía do outro lado da estrada.OJuiz Commissario desta capital tem em seu poder estes títulos e um requerimento do dicto Costa pedindo a demarcação para apossar-se definitivamente dos tais lotes, que obteve illudindo a bõa fé de dous dos Antecessores de V. Exª . Parece-me, Ex.mo Sen ${ }^{\circ}$ que dos terrenos devolutos que s'estendem de um e outro lado da estrada nas immediações do estabelecimento da Providencia, não convem por ora se conceda parte alguma a particulares, sem que primeiro seja demarcado o 
que foi concedido pelo Governo Imperial. O orçamento dessa demarcação exigido pelo Ministério de Agricultura, já lhe foi remettido pelo Antecessor de V. Exa . e é provável que não tardem as ordens para se proceder a este serviço que eu desejo apressar o mais possível. Feito isto os terrenos que sobraram poderão então ser concedidos na forma da Lei a' quem os pretender. Ocorre ainda que Costa mora do lado opposto da estrada, e nenhuma preferência pode ter no caso sobre o estabelecimento da "Providencia", com o qual confinado os dictos terrenos. E dado que fosse elle... confinante, prevaleceria sempre a consideração de estar um tracto determinado dessas terras reservado para um estabelecimento de publica utilidade, ordem que deve ser respeitada e mantida, e não illudida e frustada com intempestivas concessões. Rogo, pois, a V. Ex ${ }^{\mathrm{a}}$. que, attendendo ao exposto se assim o julgar de justiça, se digne mandar annular os dictos títulos possessórios como (...) e subrepticamente obtidos. Deus guarde a V. Ex ${ }^{a}$. Ill.mo e Ex.mo Ser. D.or Dezembargador Joaquim da Costa Barradas. M. Digno Presidente d'esta Província. + Antonio Bispo do Pará.[(Em/Ex) 4 (10) (...)]. Ofícios do Bispado.

16 Destinado ao PP Barão de Maracaju no qual pede o titulo provisório das terras do Estabelecimento Providencia, de 30/5/1883.(Lata 412, Pasta 38) IHGB: Fundo D. Macedo Costa.

17 As províncias de Sergipe, Goiás, Pernambuco, Rio Grande do Sul, Mato Grosso e Rio de Janeiro foram sedes destes institutos, ver: Imperial Instituto Fluminense de Agricultura, Imperial Instituto Bahiano de Agricultura, Imperial Instituto Sergipano de Agricultura, Sociedade Auxiliadora da Industria Nacional, Sociedade Auxiliadora da Agricultura de Pernambuco, Colonia orphanologica Christina, Colonia orphanologica Izabel, Colonia orphanologica Blasiana, Estabelecimento rural de S. Pedro de Alcantara, Sociedade Auxiliadora da Industria Nacional, Escola Veterinaria de Pelotas. Relatório apresentado á Assemblêia Geral na $4^{a}$ sessão da $18^{a}$ Legislatura pelo ministro e secretario de estado dos negocios da agricultura, commercio e obras publicas, Afonso Augusto Moreira Penna . Brazil. Typographia Nacional. Rio de Janeiro, 1884. Todos os relatórios da década de 1880 têm o mesmo teor com pequenas variações neste quesito, o relatório de 1886, p 23-24, é representativo do objetivo, metodologia e recursos envolvidos.

${ }^{18}$ NEVES, F. A. F. . UM ROMANIZADOR, A PESONAGEM DO PADRE ANTONIO DE MORAIS NA OBRA O MISSIONÁRIO DE INGLÊS DE SOUSA. In: Edilza Joana de Oliveira Fontes; José Maia Bezerra Neto. (Org.). Diálogos entre história, literatura \& memória. 1 ed. Belém: Paka-Tatu, 2007, v. 1, p. 119-138.

19 Atuando em varias frentes na busca de recursos para assistência nem sempre D. Macedo contou com a simpatia para os projetos da diocese como a permissão para as loterias a suprir a construção do Cristoforo, sendo até obstruído pelo presidente da província do Amazonas Conrad Jacob Nimeyer. Correspondência do bispado do Pará, 1887. (Lata 411, Pasta 49) IHGB: Fundo D. Macedo Costa.

${ }^{20}$ D. Macedo procurou socorrer as obras da igreja em sua diocese pedindo esclarecimento sobre prestação de contas das confrarias, de como estava sendo usado o tesouro das mesmas nas ações de assistência dos desvalidos, se as obras e instalações estão em acordo com as finalidades, se o emprego não estava sendo desviado da função prevista, caso a obra recebesse verbas suplementares do tesouro da província se havia correta aplicação, se os dirigentes e clérigos eram diligentes na execução dos serviços, se a caridade era observada na eleição das prioridades. Estes questionamentos estavam presentes na documentação no período de 1862-1886, referente ao Colégio S. Luis Gonzaga em Óbidos fundado por seu antecessor D. Afonso Torres. Suponho que esta postura possa ser indicadora da gestão do bispo sobre a área de influencia da igreja, procurando atrair financiamento para as prioridades por ele elencadas como no caso o Estabelecimento Providencia. (Lata 412, Pasta 13). Ver também sobre o financiamento para o dito colégio com apoio da lei provincial 1882, pondera $\mathrm{D}$. Macedo que o financiamento de uma obra não poderia descobrir no caso o seminário maior de Belém, principal preocupação ultramontana e raiz de muitos conflitos. Datado de 1864 (Lata 412, Pasta 55) IHGB: Fundo D. Macedo Costa.

${ }^{21}$ Ver nota 27.

${ }^{22}$ Documento de cessão de 20/1/1870. (Lata 411, Pasta 64) IHGB: Fundo D. Macedo Costa. Este tema foi tratado por Bezerra in: BEZERRA NETO, José Maia. O Recolhimento das Educandas: uma breve notícia documental (1840). Cadernos Pagu (UNICAMP), Campinas, n. 8/9, p. 407-411, 1997. . As oficinas do trabalho: representações sociais, institutos e ensino artístico no Pará (1830-1888). Ver a Educação (UFPA), Belém, v. 2, p. 41-70, 1996.

${ }^{23}$ Costa, Antonio de Macedo, Bispo do Para 1830-1891. Discurso recitado por s. exc. revm. o senr. Bispo do Pará no acto solenne da inauguração da sociedade promotora da instrucção publica no dia 24 de setembro de 1871. Belém do Para: Typ. da Boa Nova, 1873.

${ }^{24}$ Documento 1871. (Lata 412, Pasta 55) IHGB: Fundo D. Macedo Costa. 


\begin{abstract}
${ }^{25}$ Existiam no Amazonas " 75 escolas publicas para o ensino primario, sendo 43 do sexo masculino, 28 do féminino e 2 mixtas. Acham-se vagas 14 cadeiras primarias do sexo masculino e 11 do feminino. O numero de meninos matriculados foi em 1880 de 1.191 e de 575de meninas. As escolas particulares de que ha noticias unicamente 2 do sexo masculino e 3 do feminino, nas quaes se matricularam 58 meninos e 106 meninas. O Lyceu da capital funccionou com 30 estudantes matriculados. A lei provincial n. 506 de 4 de novembro de 1880 autorizou a Presidencia a reformar a instrucção publica, dando-lhe novo regulamento, e a despender a quantia de 30:000\$000 com a acquisição de terreno, plano, orçamento e primeiras obras de construcção de um edificio apropriado a este estabelecimento de instruç̧ão secundaria.A despeza com a instrucção publica nesta provincia é de 108:160\$000". No Pará "269 escolas de instrucção primaria: 187 do sexo masculino, 77 do feminino e 5 mixtas. Nestas escolas a matricula no anno de 1880 foi de 7.712 meninos e de 3.286 meninas. O colégio de Nossa Senhora do Amparo conta actualmente 222 educandas, o de 92 o numero dos meninos existentes no Instituto de Educandos Artifices Paraenses. Nos diversos annos do curso da Escola Normal matricularam-se 29 alumnos e 86 alumnas. Sem numero de 18 as escolas particulares da provincia. No anno findo a matricula dos alumnos do Lyceu Paraense elevou-se a 111. Ha noticia de 10 estabelecimentos particulares de instrucção secunda sendo 4 para o sexo masculino, e 6 para o feminino, nos quaes a matricula foi de 134 meninos e 312 meninas. Despende a provincia com o serviço da instrucção publica 372: 603\$886”. Relatório dos Negócios do IMPERIO 1881-1A, p. 76-77.

${ }^{26}$ Documento de 31/7/1863. (Lata 412, Pasta 105) IHGB: Fundo D. Macedo Costa.

${ }^{27}$ Documento de 1865. (Lata 412, Pasta 126) IHGB: Fundo D. Macedo Costa.

${ }^{28}$ Vários documentos de 1863. (Lata 412, Pasta 137) IHGB: Fundo D. Macedo Costa.
\end{abstract}

29 "Corno v. exc. sabe, foram creadas na ilha de Bailique urna parochia, duas escólas de primeiras lettras e urna collectoria provincial. Com excepção da parochia, que ainda depende da designação do sacerdote, funcionam já ali empregados por mim nomeados. S. cxc. revma. prometteu $\mathrm{m}$ um sacerdote de virtudes e saber para desempenhar aquela missão de alta importancia, e de accordo com o mesmo prelado marquei aquelle sacerdote uma gratificação mensal de duzentos mil reis com a obrigação de administrar gratis os Sacramentos na povoação do Amapá, si fôr seu ministerio solicitado pelos brazileiros ali residentes, sem que assuma a menor parcella de jurisdicçã.o n'aquele territorio, enquanto pender a questão de limites. O padre, dizem-me todos os que d'ali chegam, é a primeira necessidade do lugar, pois os habitantes se vêm obrigados a recorrer aos sacerdotes francezes de Cayetina sempre que precisam de seu auxilio, e estes sacerdotes prevalecem-se da occasião para irem lançando nos seus registros os nomes d'aquelles a quem prestam socorros espirituaes como subditos francezes, apezar de sua nacionalidade brazileira, Desde, pois, que os habitantes do Amapá poderem recorrer a um padre brazileiro, que fica-lhes mais proximo, parece que esses in convenientes cessarão, não dando lugar susceptibilidades diplomaticas, porque o padre brazileiro nenhuma jurisdicção poderá ex no territorio contestado. Felizmente o governo imperial promove a solução da questão dos nossos limites com a França, e é de esperar que a mesma solução seja digna da diplomacia das duas nações amigas". Relatorio com que o exm. sr. desembargador Joaquim da Costa Barradas passou a administração da provincia ao exm. sr. conselheiro coronel Francisco José Cardoso Junior. Pará, Typ. do Diario de Noticias, 1887, p 11.

${ }^{30}$ Relatorio com que o exm. sr. presidente, dr. Manuel Pinto de Souza Dantas Filho, passou a administração da provincia ao exm. sr. 1.o vice-presidente, dr. José da Gama Malcher. Pará, Typ. do "Liberal do Pará," $1882, \mathrm{p} 66$.

${ }^{31}$ Em 26/10/1880, o bispo do Pará pedia insistentemente para o presidente da província, Gama Abreu,não consentir a realização da procissão de Nazareth sem serem observadas a diretrizes do bispado com o devido acompanhamento do clero. (Lata 412, Pasta 80) IHGB: Fundo D. Macedo Costa.

${ }^{32}$ Relatório do Império 1883, p. 75.

${ }^{33}$ Brasil. Ministério do Império. Ministro (João Florentino Meira de Vasconcellos) Relatorio do Anno de 1884 Apresentado a Assemblea Geral Legislativa na 1 Sessão da $19^{a}$ Legislatura, p. 70(Publicado Em 1885) Inclui Annexos.

${ }^{34}$ Relatorio apresentado á Assembléa Legislativa Provincial do Amazonas na abertura da segunda sessão da decima sexta legislatura em 25 de março de 1883 pelo presidente, José Lustosa da Cunha Paranaguá. Manáos, Typ. do Amazonas, 1883.

Recebido em: $\quad$ 20/08/2011

Aprovado em: $\quad 30 / 08 / 2011$ 